\title{
Electric Podded Propulsor Propeller with Control Algorithm of Boat Based on Data Processing from Sensors
}

\author{
Suwen Li, ${ }^{1,2}$ Wanneng Yu, ${ }^{1,2^{*}}$ Chih-Cheng Chen, ${ }^{3,4 *}$ and Christopher Chun Ki Chan ${ }^{5}$ \\ ${ }^{1}$ School of Marine Engineering, Jimei University, Xiamen 361021, China \\ ${ }^{2}$ Provincial Key Laboratory of Naval Architecture \& Ocean Engineering, Xiamen 361021, China \\ ${ }^{3}$ Department of Automatic Control Engineering, Feng Chia University 40724, Taiwan \\ ${ }^{4}$ Department of Aeronautical Engineering, Chaoyang University of Technology, Taichung 413310, Taiwan \\ ${ }^{5}$ Department of Information Management of Chaoyang University of Technology, Taichung 413310, Taiwan
}

(Received July 20, 2020; accepted March 1, 2021)

Keywords: pod propeller, surface electric boat, DSP, PWM speed regulation, control system

A podded propulsor propeller (POD propulsion) with an electric power system was developed and tested on a small boat to find the feasibility of using it for vessels. The POD propulsion system was designed to use a brushless DC motor and a servo motor with a lithiumion battery. The control system, which was developed with a digital signal processor (DSP), collected and sent the data from the motors and sensors. The data were processed to create the control algorithm. A prototype boat based on the designed parameters was built with the POD propulsion system and its performance was tested. The results showed that the system had an efficient operation in terms of speed and steering. The POD propulsion system of this study is expected to provide the basic design for an efficient, stable, and eco-friendly propulsion system for large vessels.

\section{Introduction}

As oil resources are running out and environmental pollution caused by burning fossil fuels is becoming more serious, ${ }^{(1)}$ energy-saving and pollution prevention are global concerns nowadays. The contribution of the shipping industry to such problems is of increasing concern as most vessels use engines that burn diesel, heavy oil, or gas oil. Such engines cause significant air and noise pollution by burning a vast amount of fossil fuels. In addition, the engines are not fuel-efficient and require a large space to be installed. ${ }^{(2-4)}$

Thus, a new power source for engines has been studied and developed by many researchers and engineering companies. ${ }^{(5)}$ Recently, an electric podded propulsor propeller (POD propulsion) has been recognized as an innovative technology for the propulsion system of a vessel. POD propulsion has high propulsion (energy) efficiency, good maneuverability, and low space requirement as it uses electricity as the power source and does not need a large engine room. POD propulsion also allows significantly enhanced overall performance. ${ }^{(6,7)}$ Therefore, electric vessels with POD propulsion can contribute to reducing energy use and air pollution

\footnotetext{
*Corresponding author: e-mail: wnyu2007@jmu.edu.cn

** Corresponding author: e-mail: 201761000018@jmu.edu.cn https://doi.org/10.18494/SAM.2021.3028
} 
by the shipping industry. ${ }^{(8,9)}$ With the development of the electric vehicle industry, the power of secondary batteries has become sufficient for POD propulsion to replace traditional engines of vessels. POD propulsion with secondary batteries decreases the noise and vibration of the vessel considerably. Therefore, the use of POD propulsion for vessels is becoming popular, especially for inland tourism and transportation. ${ }^{(10)}$ The effective operation of POD propulsion requires the installation of many sensors to gather data for sailing (positioning, speed, and steering) and system management (electric current and circuit monitoring). The data are processed to train an algorithm to control the propulsion system of a vessel for stable operation.

Here, we propose a POD propulsion system for small boats, which comprises a brushless direct current (DC), a propulsion motor, and a motor control algorithm. The algorithm was developed and trained through the analysis of data collected from sensors installed in the motors. Then, a prototype boat with the POD propulsion system was built and tested to validate its performance for inland use.

\section{Methods}

\subsection{Hull parameters}

A prototype boat requires a simple, lightweight, and stable structure for flexible operation and durability. Thus, we calculated the main hull parameters for a boat with the POD propulsion system and a battery pack along with millimeter-wave radar, a data transfer unit (DTU), a global positioning system (GPS), surveillance cameras, and sensors. The deadweight (DWT) of the boat was about $80 \mathrm{~kg}$ with a load of $10 \mathrm{~kg}$ and a draft of $0.18 \mathrm{~m}$. The desired maximum sailing speed was 5 knots $(9.26 \mathrm{~km} / \mathrm{h})$ and the desired time for which an economic speed $[70 \%$ of the maximum revolutions per minute (RPM) or the maximum load] can be maintained was up to $6 \mathrm{~h}$ (Table 1, Fig. 1).

\subsection{Power system of prototype boat}

The power system of the prototype boat was designed to use a small POD propulsion system with the above performance requirements and the equipment installed on the hull (Fig. 2). The POD propulsion system used a pack $(12 \mathrm{~V}, 175 \mathrm{Ah})$ as the power source. The lithium-ion battery used to power the system has a high energy density, excellent charge-discharge performance,

Table 1

Main hull parameters.

\begin{tabular}{lc}
\hline Parameter & Dimension \\
\hline Length & $1.82 \mathrm{~m}$ \\
Width & $0.58 \mathrm{~m}$ \\
Height & $0.3 \mathrm{~m}$ \\
Deadweight & $80 \mathrm{~kg}$ \\
Draft & $0.18 \mathrm{~m}$ \\
Rudder area & $0.06 \mathrm{~m}^{2}$ \\
Distance from center of mass to center & $0.12 \mathrm{~m}$ \\
\hline
\end{tabular}




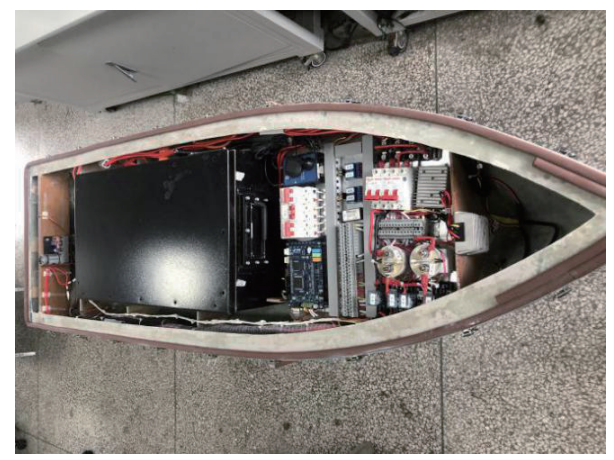

(a)

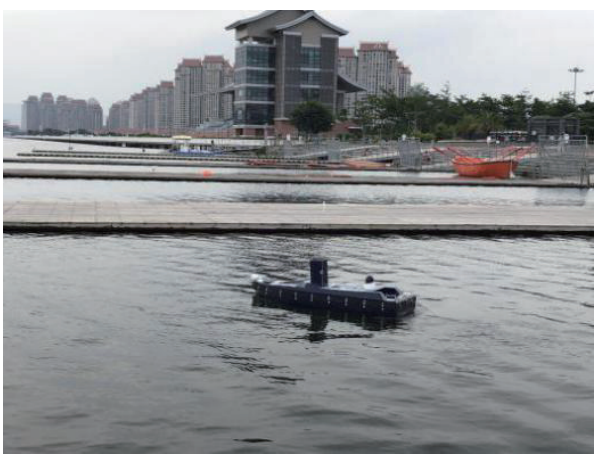

(b)

Fig. 1. (Color online) (a) Prototype boat and (b) testing the boat.

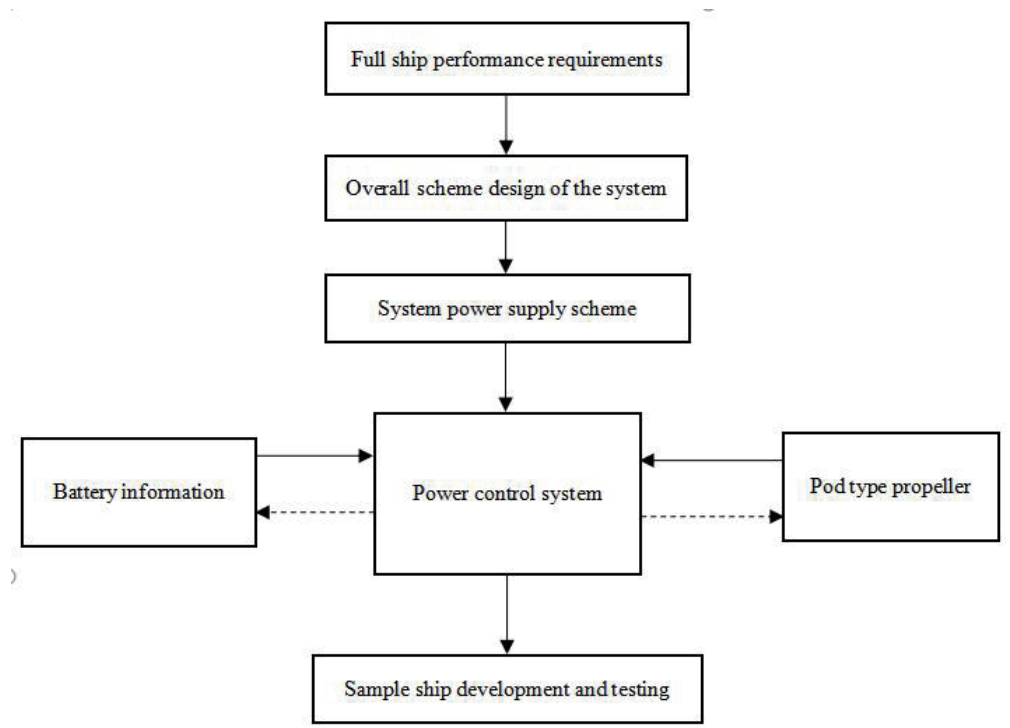

Fig. 2. Flow chart of designing the prototype boat.

high working voltage (3.6-3.9 V), large specific energy, no memory effect, negligible selfdischarge, and long cycle life. ${ }^{(11)}$ The lithium-ion battery pack operated the propulsion motor (12 V DC brushless motor), the servo motor, the digital signal processor (DSP) controller, and other electrical equipment with $12 \mathrm{~V}$ DC power. A $12 \mathrm{~V} / 24 \mathrm{~V}$ boost converter and a $12 \mathrm{~V} / 5 \mathrm{~V}$ buck converter were used for the servo motor and the DSP controller, respectively. Figure 3 shows the structure of the power system.

A brushless DC motor is widely used as the main motor of a boat owing to its high efficiency and torque and small size. ${ }^{(12)}$ However, the drive system of a brushless DC motor is complex and requires a large amount of data processing, necessitating a complex algorithm for the efficient performance of the DSP. The algorithm of the DSP controls the motors with fast processing and the responses by allocating circuit resources flexibly. ${ }^{(13,14)}$

The structure of the POD propulsion system is shown in Fig. 4. The servo motor was connected to the propulsion motor and controlled the direction of steering and the POD through 


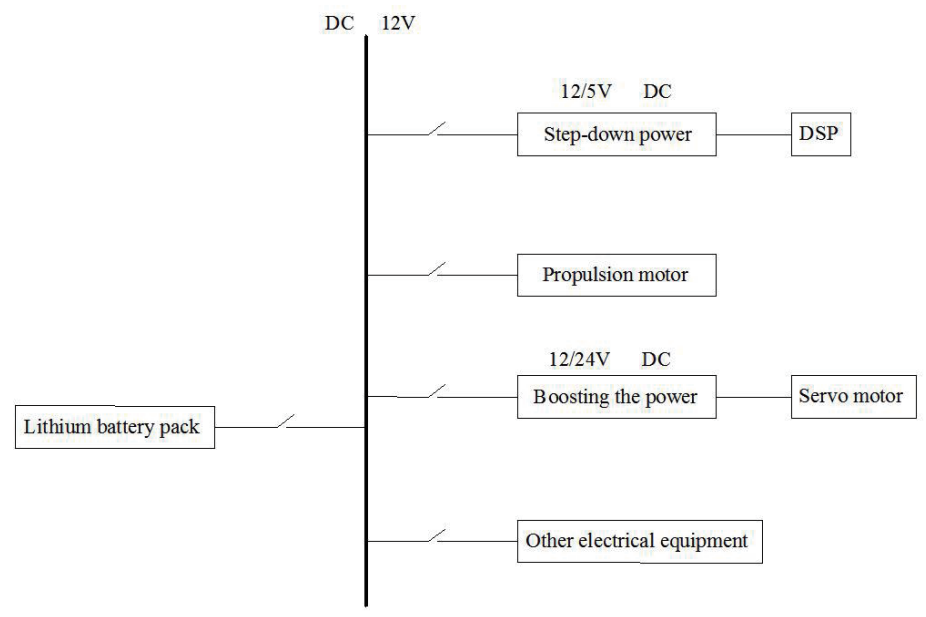

Fig. 3. Diagram of the power system of the prototype boat.

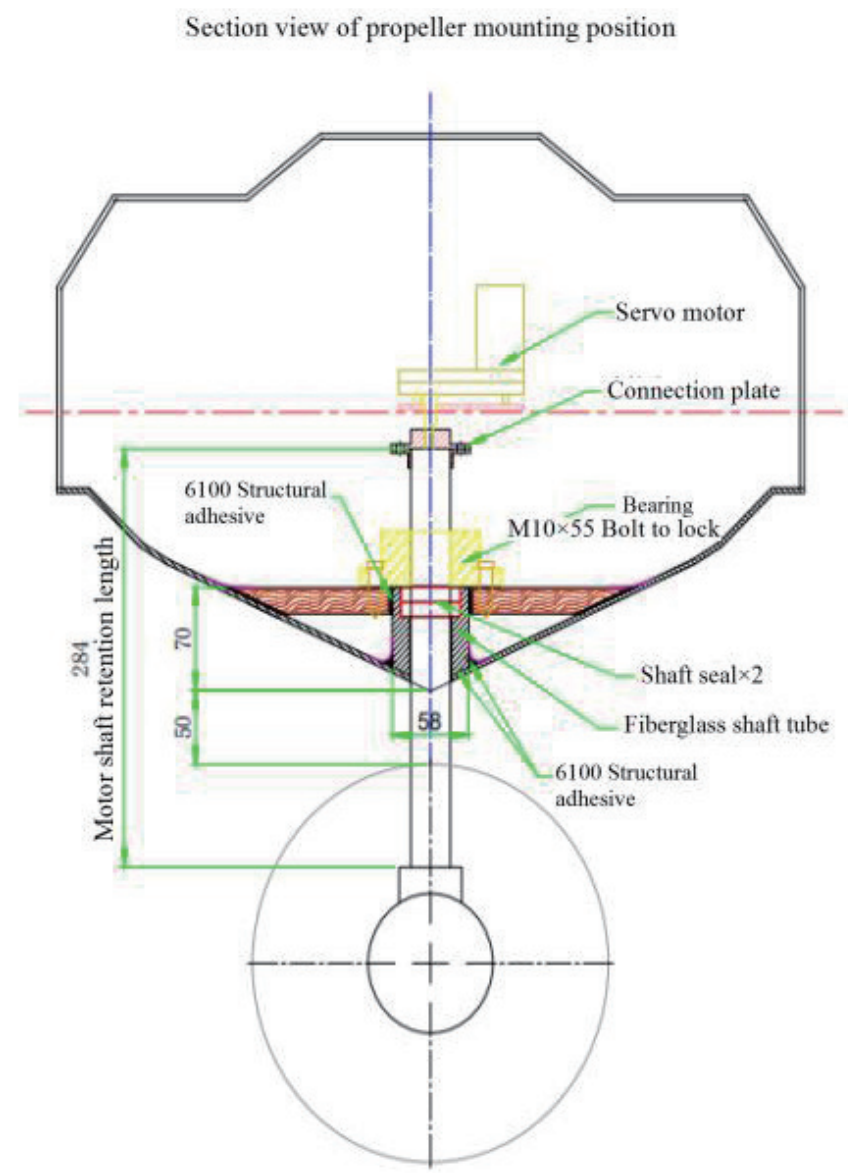

Fig. 4. (Color online) Structure of POD propulsion system.

the bracket connected to the hull. The propulsion motor of the prototype boat had a power of $480 \mathrm{~W}$ with a maximum current and speed of $60 \mathrm{~A}$ and $1100 \mathrm{RPM}$, respectively. 


\subsection{DSP control system}

The control system used a Texas Instruments TMS320F2812 DSP as the main control chip. The system controlled the full-bridge circuit: the circuits for speed-, current-, and positionmeasuring devices/sensors, and the circuit of the motors. For accurate steering, the servo motor had three closed-loop controls for high control accuracy, good reliability, flexible application, and strong adaptability: ${ }^{(15)}$ the current loop (inner loop), speed loop (outer loop), and position loop (outermost loop).

Figure 5 shows the structure of the servo motor control. The boat is steered by the following motor control.

(1) A proportional-integral-differential (PID) controller adjusts the position loop for the deviation $U_{a}$ and the feedback signal $U_{b}$ and obtains the speed reference value $V_{g}$.

(2) The PID controller calculates the current motor speed $V_{s}$ based on the feedback on the motor position. $V_{g}$ and $V_{S}$ are calculated using the speed loop in the DSP to obtain the reference voltage value $U_{i g}$.

(3) The current for the motor is detected by the current sensor. The analog signal of the current is converted to a digital one in the A/D port and sent to the DSP. Then, the voltage calculated using the current loop, $U_{i f}$, is applied and output to the current regulator. Then, the duty ratio is adjusted to control the power switch for the conduction and deadline, and finally, the brushless DC motor and the servo motor.

The steering angle is determined by the high-level duty cycle of pulse-width modulation (PWM) signals, with which the speed range is calculated to be $0.5-2.5 \mathrm{~ms}$. The DSP controller sets the high-level duty using the duty cycle calculation equation,

$$
D=\frac{T_{1 P R}-T_{1 C M P R}}{T_{1 P R}},
$$

where $D$ is the duty cycle, $T_{1 P R}$ is the $T_{1}$ cycle register, and $T_{1 C M P R}$ is the $T_{1}$ comparison register.

When the rudder angle was $0^{\circ}$, the duty cycle was $9.8 \%$. Figure 6 shows the waveform of the rudder angles of $30^{\circ}$ left, $60^{\circ}$ left, $30^{\circ}$ right, and $60^{\circ}$ right. The corresponding duty cycles were $8.9 \%, 8 \%, 10.7 \%$, and $11.5 \%$, respectively.

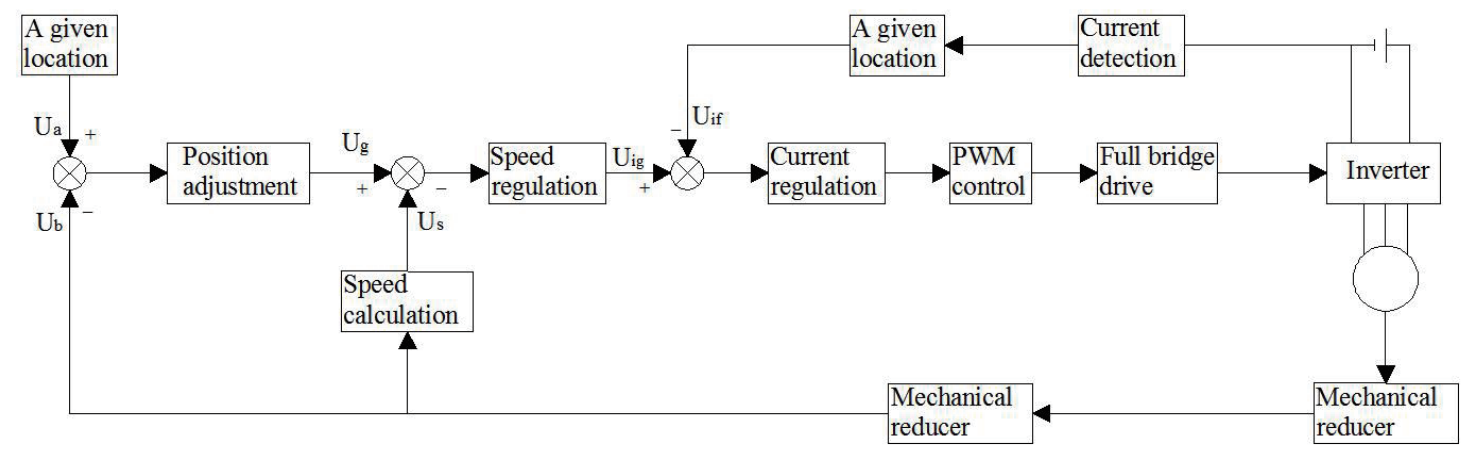

Fig. 5. Principle of servo motor control. 


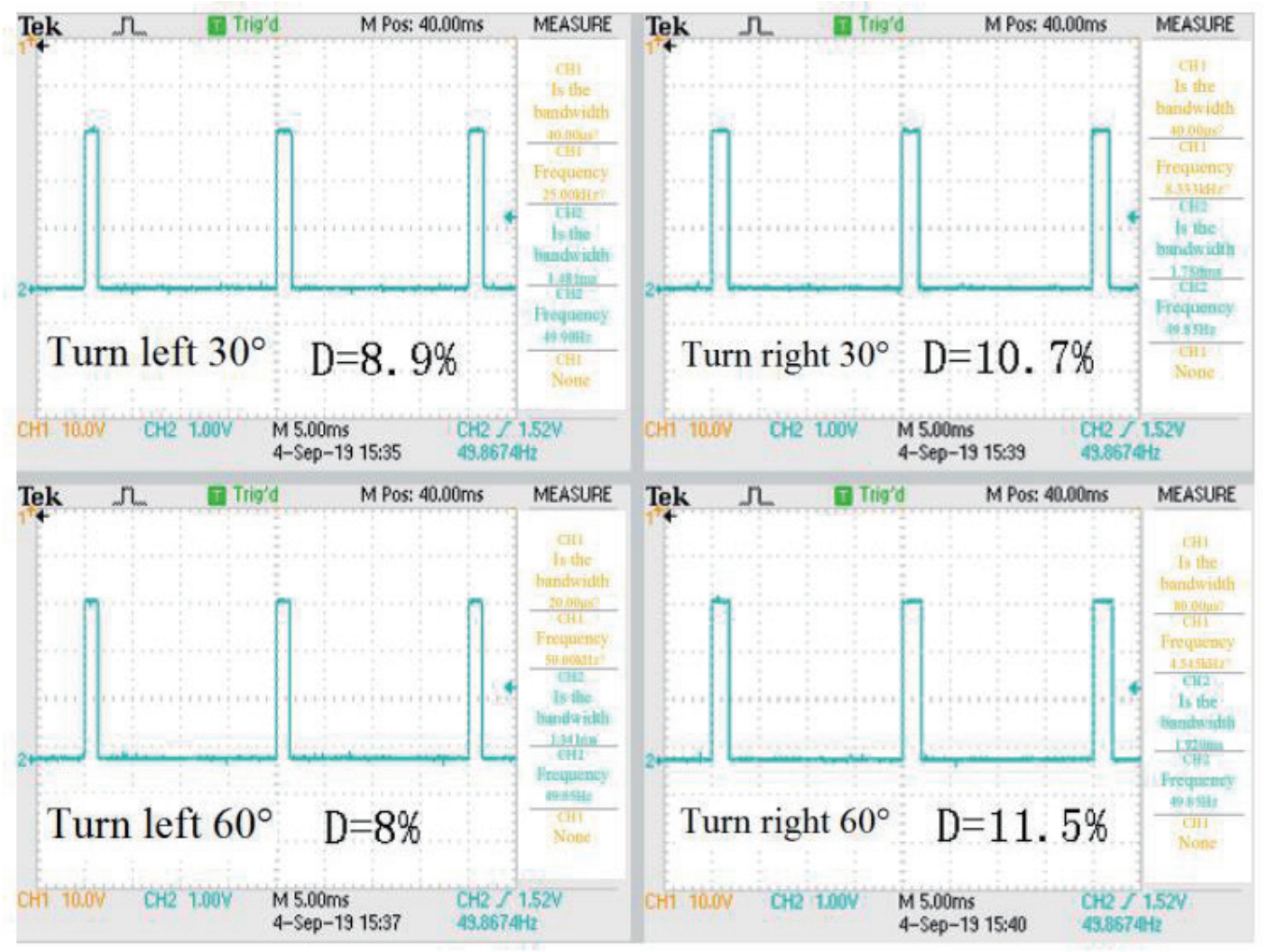

Fig. 6. (Color online) Waveform of servo motor with PWM speed regulation.

\subsection{Structure of control system}

To monitor and ensure the stable operation of the boat, it is necessary to collect, analyze, and process the data of voltages and currents. For this, a multichannel A/D converter with a builtin DSP is used to convert analog signals to digital ones. Since the range of the A/D analog input is $0-3 \mathrm{~V}$, a voltage/current transmitter is used. To improve the reliability and anti-interference ability, the communication software of a controller area network (CAN) is used for the data frame to adopt the standard frame for communication.

The software design mainly included the initialization function design of the CAN module, a sending frame function design, and a receiving frame function design. In the POD propulsion system, the CAN module of the DSP controller communicates with the battery management system (BMS) to receive the battery data. A DTU transmits the data between the host computer (cloud server) and the DSP. The DSP establishes the communication with the DTU through an RS-232 serial interface, and a Modbus remote terminal unit (Modbus-RTU) is used as the communication protocol. The connection between the DTU and the cloud server requires preconfiguration of the address and port of the cloud server. To complete the socket connection with the cloud server through point-to-point (PPP) dial-up access to a $4 \mathrm{G}$ mobile network, the DTU continuously sends the data by the DSP to the preset port of the cloud server, which includes information on the battery pack and the power system. The control instruction is 
transmitted to the DSP via the DTU through the cloud server, and the DSP issues the control instruction to each of the power equipment. The principle of the power control system is shown in Fig. 7.

\section{Results and Discussion}

To verify the steering ability of the boat, the gears for four different speed ranges were set up as follows: low speed (LS, $1.5 \mathrm{~km} / \mathrm{h}$ ), slow speed (SS, $3.6 \mathrm{~km} / \mathrm{h}$ ), half speed (HS, $6.4 \mathrm{~km} / \mathrm{h}$ ), and full speed (FS, $9.3 \mathrm{~km} / \mathrm{h}$ ) (Table 2). Figure 8 shows the speed-time diagram of the boat. The boat reached the maximum speed in each speed range in 1.2, 2.0, 2.6, and $3.2 \mathrm{~s}$. The boat stabilized these speeds in 2 to $4.5 \mathrm{~s}$ depending on the speed range. The highest speed was $9.3 \mathrm{~km} / \mathrm{h}$ with a motor speed of $1100 \mathrm{RPM}$.

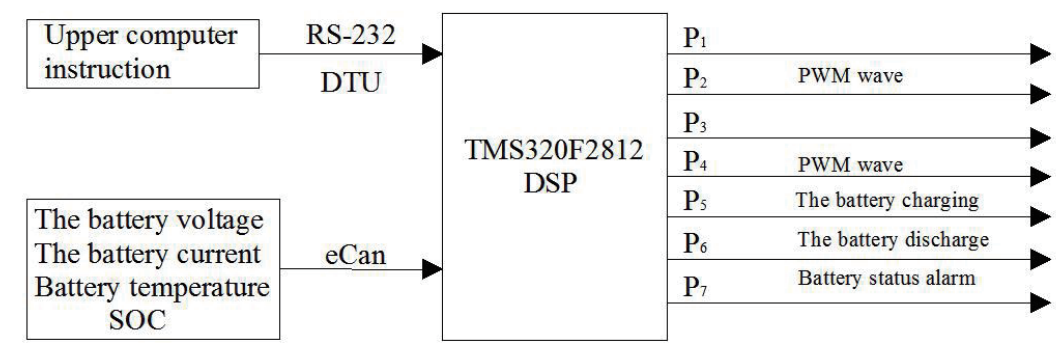

Fig. 7. Schematic diagram of power control system.

Table 2

DC brushless motor parameters.

\begin{tabular}{lcccc}
\hline Speed range & Speed $(\mathrm{km} / \mathrm{h})$ & Accelerating time $(\mathrm{s})$ & Stabilizing time $(\mathrm{s})$ & Motor speed $(\mathrm{RPM})$ \\
\hline LS & 1.52 & 1.2 & 2 & 180 \\
SS & 3.5 & 2 & 2.5 & 480 \\
HS & 6.35 & 2.6 & 3.5 & 780 \\
FS & 9.3 & 3.2 & 4.5 & 1100 \\
\hline
\end{tabular}

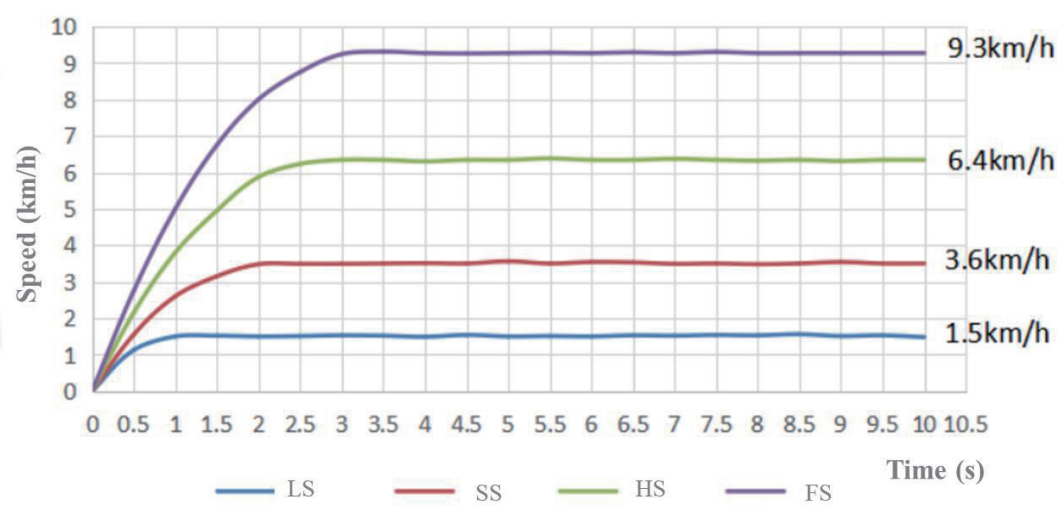

Fig. 8. (Color online) Speed-time diagram of the boat. 
The minimum turning radius was tested under each preset speed and steering angle to verify the sensitivity and accuracy of the servo motor control. The steering range of the servo motor was $-150-+150^{\circ}$ and the rudder angle range was $-60-+60^{\circ}$. The steering of the servo motor was tested for angles of $\pm 10^{\circ}, \pm 20^{\circ}, \pm 30^{\circ}, \pm 40^{\circ}, \pm 50^{\circ}$, and $\pm 60^{\circ}$. The data of the steering were stored and analyzed in a MySQL database. When the angle of the heel was less than $15^{\circ}$, the rudder angle gradually increased. Data of the speed and steering angle were computed and analyzed with the origin of the coordinates at $24.57965833 \mathrm{E}$ and $118.0829343 \mathrm{~N}$. In the test, the motion sensor fed back the position of the boat to draw its motion trajectory. Figure 9 shows the trajectories with different speeds, coordinates, and headings at the rudder angle of $60^{\circ}$. Table 3 shows the minimum turning radius at the given speeds and headings. The data revealed that the boat with the POD propulsion system showed flexible and accurate rudder rotation at different speeds.

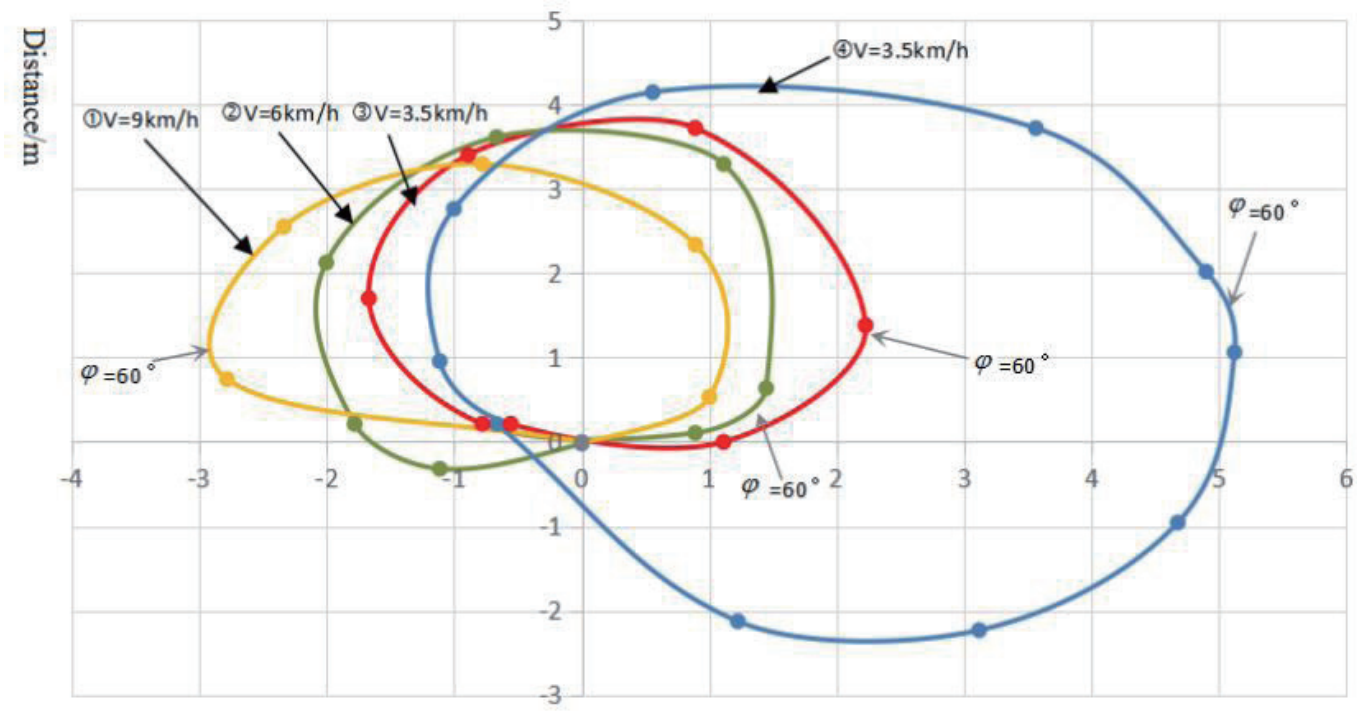

Distance/m

Fig. 9. (Color online) Trajectories of the boat at different speeds and rudder angle of $60^{\circ}$.

Table 3

Minimum turning radii for different rudder angles and speed ranges.

\begin{tabular}{lcccc}
\hline \multirow{2}{*}{ Rudder angle } & \multicolumn{4}{c}{ Turning radius } \\
\cline { 2 - 5 } & DS & SS & HS & FS \\
\hline $10^{\circ}$ & 8.23 & 6.86 & 5.17 & 6.24 \\
$20^{\circ}$ & 7.16 & 5.47 & 4.26 & 3.76 \\
$30^{\circ}$ & 5.85 & 4.62 & 3.12 & 1.85 \\
$40^{\circ}$ & 4.26 & 3.56 & 2.63 & - \\
$50^{\circ}$ & 3.56 & 2.32 & 1.94 & - \\
$60^{\circ}$ & 2.78 & 1.25 & 1.57 & - \\
\hline
\end{tabular}

Table 4

Comparison with other studies.

\begin{tabular}{lccc}
\hline Test items & This study & $\mathrm{Yu}^{(1)}$ & Kong et al. $^{(16)}$ \\
\hline $\begin{array}{l}\text { Pod propulsion } \\
\text { system }\end{array}$ & $\sqrt{ }$ & $\sqrt{ }$ & $\times$ \\
\hline Speed & $\sqrt{ }$ & $\sqrt{ }$ & $\sqrt{ }$ \\
\hline Rudder angle & $\sqrt{ }$ & $\times$ & $\times$ \\
\hline
\end{tabular}




\section{Conclusion}

A POD propulsion system and its algorithm were proposed and tested on a prototype boat in this study. The boat had a lithium-ion battery pack as the power source, a brushless DC motor for the propulsion, a servo motor for steering, and necessary equipment such as sensors, GPS, a DTU, and a DSP. The power and the propulsion system were controlled with the corresponding control algorithm, which collected and analyzed the data from the BMS and DSP. The performance of the boat at different speeds and rudder angles was stable and reliable with high control accuracy and flexible steering. The maximum speed of the boat reached $9.3 \mathrm{~km} / \mathrm{h}$. The application of the POD propulsion system allowed the efficient and stable performance of the boat and turned out to be appropriate for the required speed, steering, and operating time. Previous studies tested the availability, speed, or rudder angle of POD propulsion systems. ${ }^{(13,16)}$ In this study, we tested the POD propulsion system for different speeds and rudder angles at the same time and provided overall performance test results (Table 4). The results of this study are expected to lead to the development of a POD propulsion system for larger vessels.

\section{Acknowledgments}

This paper was supported by the National Natural Science Foundation of China (Grant No. 51679106) and Major Science and Technology Projects in Fujian Province (Grant No. 2018H6014).

\section{References}

1 W. Yu, P. Zhou, and H. Wang: Ocean Eng. 162 (2018) 34. https://doi.org/10.1016/j.oceaneng.2018.05.016

2 N. R. Ammar and I.S. Seediek: Ocean. Eng. 137 (2017) 166. https://doi.org/10.1016/j.oceaneng.2017.03.052

3 F. Balsamo, C. Capasso, G. Miccione, and O. Veneri: Energy Procedia 126 (2017) 1083. https://doi.org/10.1016/ j.egypro.2017.08.242

4 P. Luckow, E.A. Stanton, S. Fields, W. Ong, B. Biewald, S. Jackson, and J. Fisher: National Carbon Dioxide Price Forecast Synapse (Cambridge, 2016) 1-35. http://www.synapse-energy.com/sites/default/files/2016Synapse-CO2-Price-Forecast-66-008.pdf. (accessed February 2021).

5 M. Reichel: J. Mar. Sci. Technol. 25 (2020) 249. https://doi.org/10.1007/s00773-019-00644-1

6 J. Oh, S. Cho, and B. Ham: J. Mech. Eng. Sci. 31 (2017) 5761. https://doi.org/10.1007/s12206-017-1118-9

7 R. Lateb, N. Takorabet, F. Meibody-Tabar, A. Mirzaian, J. Enon, and A. Sarribouette: Proc. 2005 40th IAS Annu. Meeting Conf. Record of 2005 Industry Applications Conf. (IEEE, 2005) 1342-1349. https://doi. org/10.1109/IAS.2005.1518534

8 A. Del Pizzo, R. M. Polito, R. Rizzo, and P. Tricoli: Proc. 2010 XIX Int. Conf. Electrical Machines (ICEM, 2010) 1-6. https://doi.org/10.1109/ICELMACH.2010.5607817

9 T. Freire, D. M. Sousa, and P. J. C. Branco: Proc. 2011 EUROCON-Int. Conf. Computer as a Tool (IEEE, 2011) 1-4. https://doi.org/10.1109/EUROCON.2011.5929400

10 D.-D. Mu, G.-F. Wang, and Y.-S. Fan: J. Electr. Eng. Technol. 12 (2017) 2365. https://doi.org/10.5370/ JEET.2017.12.6.2365

11 A. Khazaee, H. A. Zarchi, and G. R. A. Markadeh: IEEE Trans. Power Electron. 35 (2020) 1194. https://doi. org/10.1109/TPEL.2019.2918711

12 L. Diao, J. Tang, P. C. Loh, W. Yin. L. Wang, and Z. Liu: IEEE Trans. Power Electron. 33 (2018) 3276. https:// doi.org 10.1109/TPEL.2017.2707639

13 R. Jadeja, A. K. Yadav, T. Trivedi, S. K. Chauhan, and V. Patel: Proc. 2016 Artificial Intelligence and Evolutionary Computations in Engineering Systems (ICAIECES, 2016) 819-834. https://doi.org/10.1007/978981-10-3174-8_68 
14 M. Niu, Y. Zhou, L. Chen, Y. Han, Y. Mi, and C. Zhang: Proc. 2018 Int. Conf. Sensing Diagnostics, Prognostics, and Control (SDPC) (IEEE, 2018) 26-29. https://doi.org/10.1109/SDPC.2018.8664926

15 L.-H. Yang: Ship Sci. Technol. 6 (2015) 155. http://doi.org/10.3404/j.issn.1672-7649.2015.06.034

16 X. J. Kong, W. Hou, C. Chen, and X. Xiong: Electron. Test 13 (2013) 31. http://doi.org/10.3969/ j.issn.1000-8519.2013.13.015

\section{About the Authors}

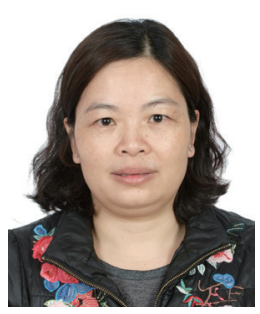

Suwen Li is a lecturer at Jimei University, China. She earned her M.S. degree in mechanical structure design from Shanghai Maritime University in 2008. Her research interests are in the area of matching between hull, propeller, and motor in vessels.

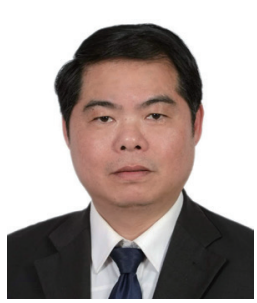

Wannneng $\mathbf{Y u}$ is a professor at Jimei University, China. He earned his Ph.D. degree in electronics and electrical driving from Shanghai Maritime University in 2010. His research interests include integrated electric propulsion systems and intelligent control of vessels.

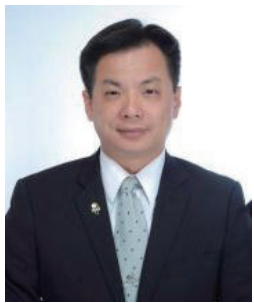

Chih-Cheng Chen is a professor at Jimei University, China. He is a senior member of IEEE. He earned his Ph.D. degree in mechatronics engineering from the National Changhua University of Education. He has published 43 articles and owns three patents. He is currently researching RFID application systems, AIOT, machine learning, and information security.

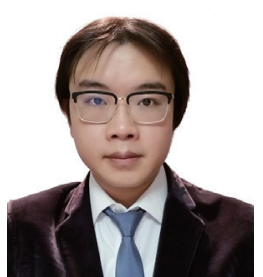

Christopher Chun Ki Chan has been an assistant professor at Chaoyang University of Technology, Taiwan, since 2019. He is an IEEE member and an active reviewer for computer science journals and conferences such as TEMS. He earned his M.S. and Ph.D. degrees from the Department of Computer Science, Ryerson University, Canada. His research interests include deep learning technology and Industry 4.0 applications.

(christopherckchan@cyut.edu.tw) 